\title{
Measurement of the pro-hormone of brain type natriuretic peptide (proBNP): methodological considerations and pathophysiological relevance
}

\author{
Aldo Clerico*, Simona Vittorini and Claudio Passino \\ Scuola Superiore Sant'Anna, Fondazione G. Monasterio \\ CNR-Regione Toscana, Pisa, Italy
}

\begin{abstract}
Recent studies demonstrated that large amounts of the prohormone peptide of brain natriuretic peptide (proBNP) can be detected in plasma of healthy subjects and in particular of patients with heart failure. As a result, a great part of B-type natriuretic peptides measured in patients with cardiovascular disease may be devoid of biological activity. These findings stimulated the set up of specific immunoassay methods for the measurement of the intact proBNP peptide. The aim of this review article is to discuss the methodological characteristics and the possible clinical relevance of specific immunoassay methods for the measurement of the proBNP peptide. From an analytical point of view, a fully automated immunoassay of proBNP has some theoretical advantages (e.g., a more stable molecule with higher molecular weight than the derived peptides) compared to the active hormone BNP. Recent studies supported the concept that the precursor proBNP might be actually considered a circulating prohormone, which can be cleaved by specific plasma proteases in BNP, the active hormone, and NT-proBNP, an inactive peptide. The peripheral processing of circulating proBNP could likely be submitted to regulatory rules, which might be impaired in patients with heart failure, opening new perspectives in the treatment of heart failure (e.g., by studying drugs inducing the cleavage of the prohormone into active BNP). Furthermore, as a future perspective, the specific assay in the same plasma sample of the intact precursor proBNP and of the biologically active peptide BNP, could allow a more accurate estimation of the production/secretion of B-type related peptides from cardiomyocytes and of the global cardiac endocrine function.
\end{abstract}

Keywords: brain type natriuretic peptide (BNP); cardiac endocrine function; corin; heart failure; immunoassay.

\footnotetext{
*Corresponding author: Prof. Aldo Clerico, MD, Department of Laboratory Medicine, Fondazione G. Monasterio CNR-Regione Toscana, Via Giuseppe Moruzzi 1, 56124 Pisa, Italy Phone: +39-0585-493569, Fax: +39-0585-493652, E-mail: clerico@ifc.cnr.it

Received May 9, 2011; accepted July 26, 2011; previously published online August 26, 2011
}

\section{Introduction}

Exactly 30 years ago, De Bold et al. (1) reported that intravenous injection of atrial extracts promotes a rapid and massive diuresis and natriuresis in rats, thus indicating that unknown endogenous substances, produced by cardiomyocytes, may have both diuretic and natriuretic properties. Only a few years after, a family of natriuretic and vasodilator peptides, named cardiac natriuretic hormones (CNHs), was isolated, purified and then chemically identified in human tissues $(2,3)$. CNHs now include atrial natriuretic peptide (ANP), brain natriuretic peptide (BNP) and their related peptides. Other natriuretic peptides, such as C-type natriuretic peptide (CNP) and urodilatin are predominantly produced and secreted by other tissues. In particular, CNP is produced predominantly by endothelium, while urodilatin by renal tubular cells by the same gene of ANP, and so this peptide is present only in the urine $(2,3)$. All natriuretic peptides share a direct diuretic, natriuretic and vasodilator effect and an inhibitory and protective action on inflammatory processes of myocardium, endothelium and smooth muscle cells, in this way modulating coagulation and fibrinolysis pathways, and inhibiting platelet activation (2-7).

From a clinical point of view, CNHs gained interest especially when it was demonstrated that the measurement of B-type-related natriuretic peptides (including BNP and NTproBNP) represents a significant improvement in the diagnostic and prognostic accuracy as well as a potential guide to treatment in the clinical setting of heart failure (8-13). For this reason, BNP/NT-proBNP assay is useful for diagnosis, risk stratification and follow-up of patients with heart failure (HF) (8-14).

Recent studies reported that many B-type-related peptides circulate in human blood (15-32). In particular, large amounts of pro-hormone peptide (i.e., proBNP) can be detected in plasma of patients with $\mathrm{HF}(15-22,25,32)$. These data may indicate that the post-translational maturation processing of BNP precursor is not efficient in heart failure $(3,20,23)$. As a result, a great part of B-type natriuretic peptides assayed in healthy subjects and patients with cardiovascular disease may be devoid of biological activity. These findings stimulated the set up of specific immunoassay methods for the measurement of the intact proBNP peptide $(18,19,22,24,25)$. The aim of this review article is to discuss the methodological characteristics and the possible clinical relevance of specific immunoassay methods for the measurement of the proBNP peptide. 


\section{Biosynthesis of B-type natriuretic peptides}

CNHs are synthesized by cardiomyocytes as pro-hormones (i.e., proANP and proBNP), which are then split into two fragments at the time of secretion from cardiomyocytes: the longer fragment includes the $\mathrm{NH}_{2}$-terminus (NT-proANP and NT-proBNP), while the shorter one (i.e., $\mathrm{COOH}$-terminus fragment) represents the active hormone (ANP and BNP).

In particular, human BNP is synthesized as a 134-amino acid (aa) precursor protein (pre-proBNP) and is subsequently processed to form a 108-aa propeptide, named proBNP. The propetide hormones of the cardiac natriuretic peptides can be enzymatically cleaved by proprotein convertases produced in the cardiomyocytes, such as corin and furin (3). ProBNP is then processed to form the 76-aa N-terminal peptide (i.e., NT-proBNP) and the biologically active 32-aa C-terminal peptide (i.e., $\mathrm{BNP}_{1-32}$ ) (Figure 1). Some of the biosynthesized pro-hormone (proBNP ${ }_{1-108}$ ) is $O$-glycosylated within the Golgi apparatus $(3,28-31)$. If $O$-glycosylation does not occur, proBNP ${ }_{1-108}$ can be cleaved to $\mathrm{BNP}_{77-108}$ and NTproBNP ${ }_{1-76}$ by the processing enzymes within the transGolgi network. If $O$-glycosylation occurs, glycosylatedproBNP ${ }_{1-108}$ cannot be cleaved, and uncleaved glycosylated proBNP ${ }_{1-108}$ is secreted into the circulation. Finally, a smaller part of intact pro-hormone is not glycosylated and cleaved, and so this peptide can be present into circulation in intact form as proBNP ${ }_{1-108}$. As indicated in the Figure 1, the glycosylation on the threonyl residue in position 71 (Thr 71) may regulate pro-hormone cleavage by either blocking or guiding endoproteolytical enzymes $(3,31)$.

\section{Circulating B-type-related peptides: biochemical characteristics}

According to the biosynthetic pathways described above, in addition to the bioactive hormone BNP, a huge number of circulating proBNP-derived fragments can be identified by chromatographic procedures in plasma of experimental animals and patients with $\operatorname{HF}(3,19,20,26,27,32)$. Moreover, the proBNP ${ }_{1-108}$ and NT-proBNP ${ }_{1-76}$ (and probably also other shorter peptides derived from these precursors) are present in plasma in both glycosylated and non-glycosylated form, especially in plasma samples of patients with heart failure $(3,20,29)$.

Some studies suggested that proBNP may be the major BNP-immunoreactive form in human blood, especially in patients with congestive heart failure (18-20, 32). In particular, Seferian et al. (29) recently reported that the plasma pool of the endogenous NT-proBNP contains a small portion (about 5\%) of non-glycosylated or incompletely glycosylated protein, and that this portion can be detected by antibodies specific to the central part of the molecule.

A still open question is whether the circulating proBNP is also present in polymer form, such as trimer $(26,27)$, or not (20). Some more recent studies seem to indicate that the high-molecular forms of proBNP, found in older studies, were more probably due to the highly glycosylated forms of the precursor peptide rather than to the polymerization forms of the peptide (20).

It is usually assumed that the active peptide $\mathrm{BNP}_{1-32}$ should have a shorter plasma half-life and consequently lower plasma concentration, compared to proBNP ${ }_{1-108}$ and NTproBNP $_{1-76}$ (Table 1) $(2,3,16-18)$. However, there is no study set up with the specific aim to accurately evaluate and compare the respective plasma half-life of BNP, NT-proBNP and proBNP in vivo in humans, but there are only a few studies available in the literature, which use experimental animal models. Using an experimental model in sheep, Pemberton et al. (33) reported that the plasma half-life of BNP is about $4.8 \pm 1.0 \mathrm{~min}$ in vivo, while that of NT-proBNP was $69.6 \pm 10.8 \mathrm{~min}$. Using an experimental rat model, Semenov et al. (34) recently reported that the terminal half-life in vivo for human glycosylated proBNP was $9.0 \pm 0.5$ min compared with $6.4 \pm 0.5 \mathrm{~min}$ for BNP. Moreover, the terminal half-life was $15.7 \pm 1.4 \mathrm{~min}$ and $15.5 \pm 1.3 \mathrm{~min}$ for glycosylated and non-glycosylated forms of NT-proBNP, respectively (34).

\section{The proBNP assay: methodological considerations}

As hypothesized several years ago (35), but only recently demonstrated (36), all immunoassays, which were considered specific for BNP or NT-proBNP peptides, actually show some cross-reactivity with proBNP. From an analytical point of view, this finding points out an important methodological problem: the need to set up more specific immunoassay methods, not only for the biologically active peptide $\mathrm{BNP}_{1-32}$, but also for all the other B-type related peptides, including the precursor proBNP ${ }_{1-108}$.

Considering the proBNP assay, some different methodological approaches may be considered for the measurement of the peptide (35). In plasma or tissue extracts, proBNP was usually isolated by means of chromatographic procedures, in particular by HPLC, and then identified and measured by immunoassay or more accurately by mass spectrometry $(16-32,35)$. These methods are highly specific for the peptide, but also complex, time consuming and not available for the clinical laboratory routine (35). To solve these problems, at least three different methodological approaches were developed with the aim to set up a highly specific immunoassay method for the measurement of proBNP $(18,24$, 37).

Goetze et al. (24) set up a radioimmunoassay (RIA) for proBNP assay based on the measurement of plasma treated with trypsin, which cleaves all proBNP-related peptides to the small 1-21 fragment. The aim of these authors was to develop a processing-independent analysis (PIA) for accurate quantification of proBNP and its fragments in plasma. This method uses an antibody specific for a processingindependent epitope of human proBNP. This antibody was directed against the first 10 amino acids of proBNP peptide and the same peptide, radio-iodinated with chloramines-T, was used as a tracer in the RIA. Using this method, these authors determined the total concentration of proBNP and its 


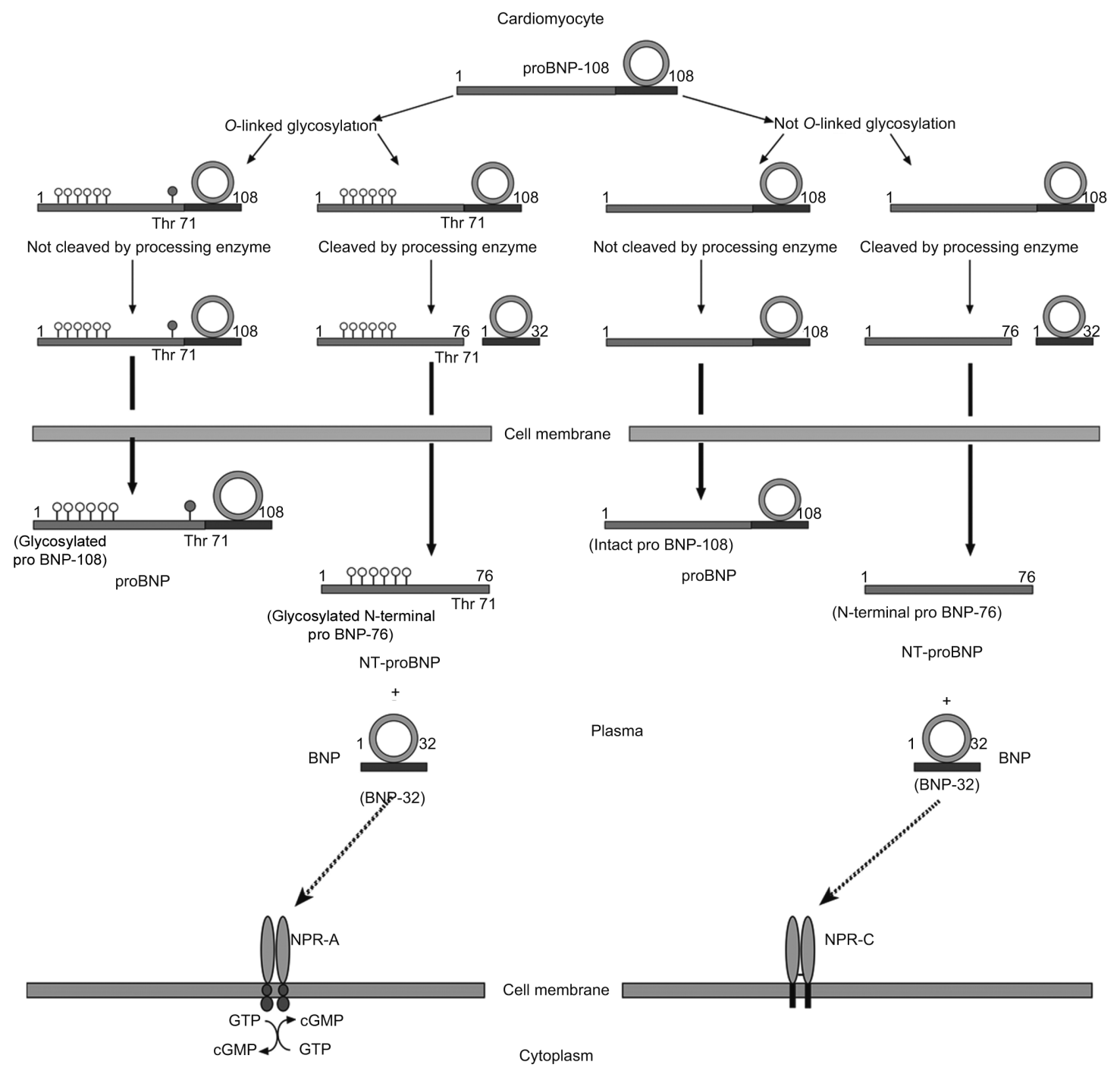

Figure 1 Schematic representation of biosynthesis, secretion and distribution of B-type related natriuretic peptides.

Some of the biosynthesized pro-hormone (proBNP-108) is $O$-glycosylated within the Golgi apparatus. If $O$-glycosylation does not occur, proBNP-108 can be cleaved to BNP-32 and NT-proBNP-76 by the processing enzymes within the trans-Golgi network. If $O$-glycosylation occurs, glycosylated-proBNP-108 cannot be cleaved, and uncleaved glycosylated proBNP-108 is secreted into the circulation. Finally, a smaller part of intact pro-hormone is not glycosylated and cleaved, and so this peptide can be present into circulation in intact form as proBNP-108. As indicated in the Figure, the glycosylation on the threonyl residue in position 71 (Thr 71) could regulate pro-hormone cleavage by either blocking or guiding endoproteolytical enzymes [see the reference (3) for more details]. Only $\mathrm{BNP}_{1-32}$, which is the active hormone, is able to bind the specific receptors, NPR-A and NPR-C. NPR-A is a guanylate cyclase-coupled receptor, which mediates the biological effects of cardiac natriuretic peptides. NPR-C, not coupled to a guanylate cyclase, has essentially a clearance function for all natriuretic peptides [see the reference (2) for more details].

products in healthy volunteers and HF patients, showing that proBNP values were greatly higher in patients (24). However, this RIA cannot be recommended for the clinical routine because this assay requires a preliminary treatment of plasma samples with trypsin, a very long incubation time (i.e., up to 5 days), and the use of radiolabeled material. Furthermore, it is theoretically conceivable that this RIA measures all the peptides containing the N-terminal part of the precursor proBNP ${ }_{1-108}$, and so even the NT-proBNP. As a consequence, for an accurate measurement of circulating levels of the intact proBNP ${ }_{1-108}$ is also necessary to accurately and independently assay the NT-proBNP concentra- tion. From a pathophysiological point of view, it is important to note that this RIA can allow an estimation of the overall production by cardiomyocytes of the precursor proBNP, including both the intact circulating proBNP ${ }_{1-108}$ and the part of the precursor split before secretion (or in plasma) in NT-proBNP (and BNP).

Tamm et al. (37) developed a sandwich immunofluorescence assay for the quantification of BNP and its precursor proBNP. Authors reported that this immunofluorescence assay recognizes with the same efficiency the BNP as well as the recombinant glycosylated and non-glycosylated forms of proBNP (37). This immunoassay method (named "single- 
Table 1 Biochemical and physiological characteristics of BNP, NT-proBNP and proBNP peptides.

\begin{tabular}{llll}
\hline & BNP & NT-proBNP & proBNP \\
\hline Molecular mass & $3462 \mathrm{Da}$ & $8457 \mathrm{Da}^{\mathrm{a}}$ & $11900 \mathrm{Da}^{\mathrm{a}}$ \\
Amino acids & 32 & 76 & 108 \\
Biological function & Active hormone & Inactive & Pro-hormone \\
Plasma half life & $15-20$ min & $>60$ min & $>60$ min \\
Glycosylation & Not glycosylated & Highly glycosylated & Highly glycosylated \\
In vitro stability & Rapidly degraded in serum & More stable & More stable \\
Clearance mechanisms & Clearance receptors and enzymatic degradation & Enzymatic degradation & Enzymatic degradation \\
\hline
\end{tabular}

${ }^{a}$ The molecular mass (MM) of NT-proBNP and proBNP depends to the degree of glycosylation of the peptide; in the Table are reported the $\mathrm{MM}$ of non-glycosylated peptides.

epitope sandwich assay") is different from the conventional sandwich assay since it requires only one epitope for antigen immunodetection by two different monoclonal antibodies. In this novel immunoassay, the first antibody is used as a capture antibody and is specific for the region consisting of BNP amino acid residues $11-22$, which is the most stable part of the peptide and includes the biologically active cysteine ring. The second antibody is used as a detection antibody and recognizes the immune complex, including the antigen (i.e., $\mathrm{BNP}_{11-22}$ ) bound to the first antibody. In other words, the second antibody does not recognize the free antigen, but the primary immune complex, consisting of the first antibody and BNP, operates as antigen for the second antibody. It is also important to note that this immunoassay method is not theoretically specific for the intact proBNP ${ }_{1-108}$ peptide. Indeed, the single-epitope sandwich assay should also recognize all the peptides (shorter than proBNP), which include the region consisting of amino acid residues 11-22 of BNP and are also able to form a complex with the first antibody.

Giuliani et al. (18) selected a specific monoclonal antibody (named "mAb Hinge76") that recognizes the cleavage site of proBNP ${ }_{1-108}$, an epitope found only in the precursor form (see Figure 1). This monoclonal antibody recognizes the recombinant proBNP ${ }_{1-108}$ in a dose-dependent manner, without any significant cross-reactivity with either recombinant NT-proBNP ${ }_{1-76}$ or synthetic $\mathrm{BNP}_{1-32}$. These authors set up a sandwich immunoassay for the measurement of proBNP, by combining the monoclonal antibody mAb Hinge76 with a polyclonal antibody directed against $\mathrm{BNP}_{1-32}$. An automated version of this method on the BioPlex ${ }^{\text {TM }} 2200$ analyzer was then set up and their analytical characteristics were evaluated (38). More recently, some studies reported the clinical results obtained in general community (25) and in patients with heart failure (39) or chronic renal disease (40) by measuring proBNP concentrations with of this immunoassay method.

\section{Should we need the proBNP assay?}

From an analytical point of view, a fully automated immunoassay of proBNP has some theoretical advantages as biomarker (i.e., more stable molecule, higher molecular weight, lower biological variability) compared to the measurement of the active hormone BNP (Table 1). As a future perspec- tive, the simultaneous measurement in the same plasma sample with two methods, one specific for the intact precursor proBNP ${ }_{1-108}$, and the other for active peptide $\mathrm{BNP}_{1-32}$, could allow a more accurate estimation of both production/secretion of B-type related peptides from cardiomyocytes and overall activity of the cardiac endocrine function, compared to the single assay of either peptide (41). Information obtained by contemporaneous measurement of proBNP and BNP with specific assays should likely extend our present understanding of pathophysiological mechanisms linking together disease progression and cardiac endocrine dysfunction. Indeed, a recent study in ambulatory patients with chronic systolic HF showed that the combined assessment of conventional BNP and proBNP immunoassays provides additional information in determining the risk of adverse clinical outcomes, particularly in patients with low BNP values (22). However, designed studies will be necessary in order to estimate and compare the diagnostic and prognostic accuracy of specific assays for different B-type related peptides: BNP, NT-proBNP and intact proBNP, used either alone or in combination.

From a pathophysiological point of view, a blunted natriuretic response after pharmacological doses of ANP and BNP has been observed in experimental models and in patients with chronic heart failure, suggesting a resistance to the biological effects of $\mathrm{CNH}$, principally to natriuresis (2, 42, 43). As discussed in detail previously (2), resistance to the biological action of $\mathrm{CNH}$ can be attributed at least to three kinds of different causes/mechanisms, acting at prereceptor, receptor and post-receptor level, respectively.

Considering the possible causes of resistance at the prereceptor level, recent findings (16-32, 34, 44, 45) suggest that in patients with heart failure there may be an insufficient post-translation maturation of the biosynthetic precursors of B-type natriuretic peptide system. According to these findings $(16-32,34,44,45)$, it is theoretically conceivable that the active hormone (i.e., BNP) may be produced even in vivo from the circulating precursor proBNP ${ }_{1-108}$ by plasma enzyme degradation. Indeed, the soluble form of corin, a transmembrane serine protease able to cleave proBNP, is also capable of processing the circulating intact precursor of natriuretic hormones (44). Dong et al. (45) recently confirmed that soluble corin is measurable in human blood. Furthermore, these authors reported that plasma corin levels are significantly lower in heart failure patients than in healthy 
controls and that the reduction in plasma enzyme is correlated to the severity of the disease (45). Finally, Semenov et al. demonstrate that synthetic or recombinant human proBNP can be processed to active BNP in the circulating blood, when injected in the femoral vein of rats (34).

The above-mentioned studies $(16-32,34,44,45)$ open a new and more complex scenario regarding the B-type natriuretic peptides, the precursor proBNP actually acting as a circulating pro-hormone. The peripheral processing of circulating proBNP could likely be submitted to regulatory rules, which might be impaired in patients with heart failure, opening new perspectives in the treatment of heart failure. A novel pharmacological target may be pharmacodynamic actions of drugs inducing and/or modulating the maturation of the prohormone into active hormone (i.e., BNP). However, further studies are necessary to demonstrate whether proBNP may be an equivalent alternative to BNP/NT-proBNP assay or may add incremental value to these existing biomarkers of cardiac dysfunction.

\section{References}

1. de Bold AJ, Borenstein HB, Veress AT, Sonnenberg H. A rapid and potent natriuretic response to intravenous injection of atrial myocardial extract in rats. Life Sci 1981;28:89-94.

2. Clerico A, Recchia FA, Passino C, Emdin M. Cardiac endocrine function is an essential component of the homeostatic regulation network: physiological and clinical implications. Am J Physiol Heart Circ Physiol 2006;290:H17-29.

3. Goetze JP. Biosynthesis of cardiac natriuretic peptides. Results Probl Cell Differ 2010;50:97-120.

4. De Bold AJ. Natriuretic peptides gene expression and secretion in inflammation. J Invest Med 2009;57:29-32.

5. Qian JY, Haruno A, Asada Y, Nishida T, Saito Y, Matsuda T, et al. Local expression of C-type natriuretic peptide suppresses inflammation, eliminates shear stress-induced thrombosis, and prevents neointima formation through enhanced nitric oxide production in rabbit injured carotid arteries. Circ Res 2002;91: 1063-9.

6. Scotland RS, Cohen M, Foster P, Lovell M, Mathur A, Ahluwalia A, et al. C-type natriuretic peptide inhibits leukocyte recruitment and platelet-leukocyte interactions via suppression of P-selectin expression. Proc Natl Acad Sci USA 2005;102: 14452-7.

7. Villar IC, Panayiotou CM, Sheraz A, Madhani M, Scotland RS, Nobles M, et al. Definitive role for natriuretic peptide receptor$\mathrm{C}$ in mediating the vasorelaxant activity of C-type natriuretic peptide and endothelium-derived hyperpolarising factor. Cardiovasc Res 2007;74:515-25.

8. Clerico A, Fontana, M, Ripoli A, Emdin M. Clinical relevance of BNP measurement in the follow-up of patients with chronic heart failure. Adv Clin Chem 2009;48:163-9.

9. Doust JA, Glasziou PP, Pietrzak E, Dobson AJ. A systematic review of the diagnostic accuracy of natriuretic peptides for heart failure. Arch Intern Med 2004;164:1978-84.

10. Doust JA, Pietrzak E, Dobson A, Glasziou P. How well does B-type natriuretic peptide predict death and cardiac events in patients with heart failure: systematic review. Br Med J 2005; 330:625.
11. Ewald B, Ewald D, Thakkinstian A, Attia J. Meta-analysis of $\mathrm{B}$ type natriuretic peptide and $\mathrm{N}$-terminal pro B natriuretic peptide in the diagnosis of clinical heart failure and population screening for left ventricular systolic dysfunction. Intern Med J 2008;38:101-13.

12. Porapakkham P, Porapakkham P, Zimmet H, Billah B, Krum H. B-type natriuretic peptide-guided heart failure therapy: a metaanalysis. Arch Intern Med 2010;170:507-14.

13. Dickstein K, Cohen-Solal A, Filippatos G, McMurray JJ, Ponikowski P, Poole-Wilson PA, et al. ESC committee for practice guidelines (CPG). SC guidelines for the diagnosis and treatment of acute and chronic heart failure 2008: the task force for the diagnosis and treatment of acute and chronic heart failure 2008 of the European society of cardiology. Developed in collaboration with the heart failure association of the ESC (HFA) and endorsed by the European society of intensive care medicine (ESICM). Eur J Heart Fail 2008;10:933-89.

14. Jessup M, Abraham WT, Casey DE, Feldman AM, Francis GS, Ganiats TG, et al. 2009 focused update: ACCF/AHA guidelines for the diagnosis and management of heart failure in adults: a report of the American college of cardiology foundation/American heart association task force on practice guidelines: developed in collaboration with the international society for heart and lung transplantation. Circulation 2009;119:1977-2016.

15. Liang F, O'Rear J, Schellenberger U, Tai L, Tai L, Lasecki M, et al. Evidence for functional heterogeneity of circulating B-type natriuretic peptide. J Am Coll Cardiol 2007;49:1071-8.

16. Goetze JP. Biochemistry of pro-B-type natriuretic peptidederived peptides: the endocrine heart revisited. Clin Chem 2004;49:1503-10.

17. Goetze JP. ProBNP-derived peptides in cardiac disease. Scand J Clin Lab Invest 2004;64:497-510.

18. Giuliani I, Rieunier F, Larue C, Delagneau JF, Granire C, Pau $\mathrm{B}$, et al. Assay for measurement of intact B-type natriuretic peptide prohormone in blood. Clin Chem 2006;52:1054-61.

19. Seferian KR, Tamm NN, Semenov AG, Mukharyamova KS, Tolstaya AA, Koshkina EV, et al. The brain natriuretic peptide (BNP) precursor is the major immunoreactive form of BNP in patients with heart failure. Clin Chem 2007;53:866-73.

20. Hammerer-Lercher A, Halfinger B, Sarg B, Mair J, Puschendorf B, Griesmacher A, et al. Analysis of circulating forms of proBNP and NT-proBNP in patients with severe heart failure. Clin Chem 2008;54:858-65.

21. Goetze JP, Rehfeld JF. Peptide hormones and their prohormones as biomarkers. Biomark Med 2009;3:335-8.

22. Dries DJ, Ky B, Wu A, Rame JE, Putt M, Cappola T. Simultaneous assessment of unprocessed ProBNP 1-108 in addition to processed BNP32 improves risk stratification in ambulatory patients with systolic heart ailure. Circ Heart Fail 2010;3: 220-7.

23. Goetze JP, Kastrup J, Rehfeld JF. The paradox of increased natriuretic hormones in congestive heart failure patients: does the endocrine heart also fail in heart failure? Eur Heart $\mathrm{J}$ 2003;24:1471-2.

24. Goetze JP, Kastrup J, Pedersen F, Rehfeld JF. Quantification of pro-B-type natriuretic peptide and its products in human plasma by use of an analysis independent of precursor processing. Clin Chem 2002;48:1035-42.

25. Macheret F, Boerrigter G, McKie P, Costello-Boerrigter L, Lahr B, Heublein D, et al. Pro-B-type natriuretic peptide 1-108 circulates in the general community: plasma determinants and detection of left ventricular systolic dysfunction. J Am Coll Cardiol 2011;57:1386-95. 
26. Shimizu H, Masuta K, Aono K, Asada H, Sasakura K, Tamaki $\mathrm{M}$, et al. Molecular forms of human brain natriuretic peptide in plasma. Clin Chim Acta 2002;316:129-35.

27. Shimizu H, Masuta K, Asada H, Sugita K, Sairenji T. Characterization of molecular forms of probrain natriuretic peptide in human plasma. Clin Chim Acta 2003;334:233-9.

28. Schellenberger U, O'Rear J, Guzzetta A, Jue RA, Protter AA, Pollitt NS. The precursor to B-type natriuretic peptide is an Olinked glycoprotein. Arch Biochem Biophys 2006;451:160-6.

29. Seferian KR, Tamm NN, Semenov AG, Tolstaya AA, Koshkina EV, Krasnoselsky MI, et al. Immunodetection of glycosylated NT-proBNP circulating in human blood. Clin Chem 2008;54: 866-73.

30. Crimmins DL, Kao JL. A glycosylated form of the human cardiac hormone pro B-type natriuretic peptide is an intrinsically unstructured monomeric protein. Arch Biochem Biophys 2008;475:36-41.

31. Semenov AG, Postnikov AB, Tamm NN, Seferian KR, Karpova NS, Bloshchitsyna MN, et al. Processing of pro-brain natriuretic peptide is suppressed by $\mathrm{O}$-glycosylation in the region close to the cleavage site. Clin Chem 2009;55:489-98.

32. Miller WL, Phelps MA, Wood CM, Schellenberger U, Van Le A, Perichon R, et al. Comparison of mass spectrometry and clinical assay measurements of circulating fragments of B-Type natriuretic peptide in patients with chronic heart failure. Circ Heart Fail 2011;4:355-60.

33. Pemberton CJ, Johnson ML, Yandle TG, Espiner EA. Deconvolution analysis of cardiac natriuretic peptides during acute volume overload. Hypertension 2000;36:355-9.

34. Semenov AG, Seferian KR, Tamm NN, Artem'eva MM, Postnikov $\mathrm{AB}$, Bereznikova $\mathrm{AV}$, et al. Human pro-B-type natriuretic peptide is processed in the circulation in a rat model. Clin Chem 2011;57:883-90.

35. Clerico A, Del Ry S, Giannessi D. Measurement of natriuretic cardiac hormones (ANP, BNP, and related peptides) in clinical practice: the need for a new generation of immunoassay methods. Clin Chem 2000;46:1529-34.

36. Luckenbill KN, Christenson RH, Jaffe AS, Mair J, OrdonezLlanos J, Pagani F, et al. Cross-reactivity of BNP, NT-proBNP, and proBNP in commercial BNP and NT-proBNP assays: preliminary observations from the IFCC committee for standardi- zation of markers of cardiac damage. Clin Chem 2008;54: 619-21.

37. Tamm NN, Seferian KR, Semenov AG, Mukharyamova KS, Koshkina EV, Krasnoselsky MI, et al. Novel immunoassay for quantification of brain natriuretic peptide and its precursor in human blood. Clin Chem 2008;54:1511-8.

38. Wu AH, Smith A, Rame E, Wians F, Minard F, Giuliani I, et al. Analytical assay characterization for 1-108 pro-B-type natriuretic peptide on the BioPlex 2200 analyzer. Clin Chim Acta 2009;408:143-4.

39. Miller WL, Burnett JC, Jr, Hartman KA, Hodge DO, Giuliani I, Minard F, et al. Role for precursor Pro-B type natriuretic peptide in assessing response to therapy and prognosis in patients with decompensated heart failure treated with nesiritide. Clin Chim Acta 2009;406:119-23.

40. Bargnoux AS, Klouche K, Fareh J, Barazer I, Villard-Saussine $\mathrm{S}$, Dupuy $\mathrm{AM}$, et al. Prohormone brain natriuretic peptide (proBNP), BNP and N-terminal-proBNP circulating levels in chronic hemodialysis patients. Correlation with ventricular function, fluid removal and effect of hemodiafiltration. Clin Chem Lab Med 2008;46:1019-24.

41. Emdin M, Passino C, Clerico A. Natriuretic peptide assays revisited: do we need pro-B-type natriuretic peptide? J Am Coll Cardiol 2011;57:1396-8.

42. Iervasi G, Clerico A, Berti S, Pilo A, Biagini A, Bianchi R, et al. Altered tissue degradation and distribution of Atrial Natriuretic Peptide in patients with idiopathic dilated cardiomyopathy and its relationship with clinical severity of the disease and sodium handling. Circulation 1995;91:2018-27.

43. Clerico A. Pathophysiological and clinical relevance of circulating levels of cardiac natriuretic hormones: is their assay merely a marker of cardiac disease? Clin Chem Lab Med 2002; 40:752-60.

44. Knappe S, Wu F, Masikat MR, Wu Q. Functional analysis of the transmembrane domain and activation cleavage of human corin: design and characterization of a soluble corin. J Biol Chem 2003;278:52363-70.

45. Dong N, Chen S, Yang J, He L, Liu P, Zheng D, et al. Plasma soluble corin in patients with heart failure. Circ Heart Fail 2010;3:207-11. 